\title{
Research on Spiritual Endowment for Empty Nesters in Rural Area from the Perspective of Active Aging
}

\author{
Bo Xing \\ Xi'an Peihua University, Xi’an, Shaanxi, China
}

Keywords: active aging; empty nesters in rural area; spiritual endowment

\begin{abstract}
With the development of economic society, problems in spiritual endowment for empty nesters in rural area are increasingly prominent, and it is difficult for family and society to entirely undertake the responsibility of spiritual endowment. The elderly are not only the object, also the subject of endowment. Therefore, in responding to the aging population, it is required to fully explore the endowment potential of the aged people, mobilize the initiative of the aged, make them become the subject, and cultivate their awareness of active spiritual support.

As for spiritual endowment for empty nester, at present, most researchers excessively take the elderly as the passive group for endowment and as the object, however, ignore their role of subject; paying excessive attention to the responsibility that shall be undertaken by supporter, and ignoring the communication between the needs of both sides [1]. Based on this problem, in this paper, in order to satisfy spiritual requirements of the elderly, it is necessary for family and society to provide care and services, more importantly, to "mobilize their life potential", cultivate their awareness of active spiritual endowment, and make them become the subject of spiritual endowment.
\end{abstract}

\section{The Connotation of Active Aging}

The theory of active aging was put forward by international society to response to population aging. According to Active Aging -A Policy Framework, active aging refers to the process of giving full play to the opportunity of healthy, participation and guarantee in order to improve the living quality when people are in old age [2].

The concept of active aging emphasizes that the elderly are the beneficiary of social development, the contributor and the participant, confirming the social status of the elderly. The connotation of active aging is rich, suitable for aged individual, and aged group and the society [3]. From the perspective of individual aged people, active aging requires the elderly to remain physically and psychologically healthy and to face the aged life; from the aged group, it means that the elderly, as main resources of family and society, shall contribute to the society. For society, active aging means that in the rapid aging, the society shall be able to response to negative impact of aging, remain sustainably healthy and stable development, and transform the elderly to positive strength with positive attitude, policy and actions so as to promote the guarantee, healthy, participation and development of the elderly. Active aging has been included in political declaration of the Second World Assembly on Aging as an international strategy for the world to response to aging population.

Today, due to the weakening endowment function of family and insufficient social spiritual support, active aging undoubtedly provides a new thinking for spiritual endowment for empty nesters in rural areas.

\section{Analysis on Current Status of Spiritual Endowment for Empty Nesters in Rural Area}

\subsection{The tedious spiritual and cultural life}

According to surveys, the range of activity for most empty nesters in rural areas are family and community, so their leisure life is tedious and boring. Among 100 investigated empty nesters in 
rural area, there are $66.7 \%$ of empty nesters living a leisure life mainly with chatting, then with watching TV, accounting for $21 \%$. Besides, leisure life mainly includes doing housework, playing poker, playing chess, listening to the radio, gardening, poultry rearing and so on. As for causes, on one hand, due to the insufficient service facilities of spiritual endowment in rural communities, most villages have not establish spiritual endowment institutions, such as recreation center for the elderly, psychological counseling center for the elderly and association of aged people, difficult to meet the requirements of spiritual endowment for empty nesters; on the other hand, because of the lower degree of education, most empty nesters in rural areas cannot accept new things easily, cannot spend their leisure life on Internet, reading books or reading newspapers as the elderly in urban area, which results in the psychological emptiness of empty nesters in rural areas to some extent [4].

\subsection{The strong feeling of loneliness and inadequate care from children}

The fourth sampling survey on living conditions of China's urban and rural aged people shows that loneliness is the biggest problem troubling empty nesters in rural area. With the increase of age and decline of labor capacity, it is difficult for empty nesters to obtain the sense of value form labor. After returning to family, spiritual consolation from children becomes the important support for the elderly to adapt to the transformation of their social role to a great extent. However, in real life, rural young people have to leave their hometown for work or learning outside, thus, empty nesters obtain less and less spiritual consolation, even none; What's more, influenced by traditional concepts, in rural area, the nursing idea is limited to material support, without realizing the significance of spiritual support, thus ignoring emotional communication and spiritual consolation between the elderly. The long-term lonely life leads to the lack of spiritual support and gradually increasing feeling of loneliness.

\subsection{The low social participation}

According to the actual investigation on the willingness of aged people to participate in cultural and recreational activities organized by community, to care about making village affairs public, to participate in village committee election, to represent the elderly in village to report the situation of aged people to higher organization and so on, the results show that besides party members of empty nesters, only a few aged people are willing to involved in social participation, their enthusiasm is not high, and most aged people hold an indifferent attitude towards social participation, unless there is necessary requirement from village committee. The first reason is physical cause. Some empty nesters have poor physical conditions and suffer from diseases, so they cannot be involved in social participation; secondly, it is the constraint of educational degree. The group characteristics of empty nesters in rural area are mainly shown in old age, low education background, and vulnerable psychology, and the capacity of social participation is relatively lower, which constrains their social participation; thirdly, the positioning of the elderly from the society is negative. For a long period, the elderly are considered the group to be nursed, their dominant role is ignored and the opportunity of re-employment for the elderly is fewer.

\subsection{The inadequate awareness of self-spiritual endowment}

In Chinese traditional culture, the spiritual life of aged people is centered with children and grandchildren. Influenced by traditional concept of "bringing up sons to support parents in their old age", most empty nesters in rural area rely seriously on children in spiritual endowment. Especially, some aged people consider their children as the only spiritual support, focusing and relying too much on them, with excessively high requirement, not only troubling themselves, also bringing much pressure on children, which show the inadequate awareness of self-spiritual endowment. It shall be pointed out that Rights Protection Law of the People's Republic of Elderly People stipulates that "Family members shall care about spiritual requirements of the elderly, and cannot ignore and neglect the elderly. Family members living apart from the elderly shall visit them often and meet their spiritual requirements." The legal regulation is recommendable and reasonable, however, it is also necessary for us to see the other side of problem. This repetitive promotion, whereas, imperceptibly consolidates the relying on children from the elderly and weakens their awareness of 
self-spiritual endowment.

\section{Measures and Suggestions of Spiritual Endowment for Empty Nesters in Rural Area from Active Aging}

Empty nesters in rural area are not only the object of nursing, also the subject. To satisfy their requirements for spiritual support, family and society shall provide care and services. More importantly, it is necessary to inspire the life potential of elderly people and cultivate their active awareness of spiritual endowment so as to make empty nesters become the subject of spiritual endowment.

\subsection{From the society: The society shall establish platforms to promote the cultivation of spiritual endowment awareness and capacity of elderly people}

\subsubsection{To increase the investment in spiritual endowment for the elderly in rural area.}

First of all, based on community, it is necessary to establish and improve service facilities of spiritual endowment in rural community, such as senior citizens activity center, library for the elderly, fitness center for the elderly, chess and card room for the elderly and so on, so as to provide platform of fitness, recreation and learning for the elderly to be involved in cultural and sports activities. These places can be constructed with investment from the government, and also can be transformed from those more and more vacant houses in villages in the form of leasing [5]. Secondly, it is required to set up psychological counseling center for the aged people and association of aged people to help them safeguard their rights and solve problems in psychological healthy. The government shall allocate enough full-time staff and provide support in fund.

\subsubsection{To create platforms for empty nesters to exert their own advantages.}

Firstly, to provide appropriate positions for empty nesters in rural area to realize the productive aging. For most of them, their labor capacity and energy fades to certain extent, however, their longing for participating in labor never weaken and happiness obtained from labor is irreplaceable [6]. Therefore, it is necessary to provide appropriate jobs for them, including civil mediation, reception office duty, public security inspection in the daytime, garden management, health supervision and so on. In this way, the elderly earn more money and obtain happiness and satisfaction from labor. Secondly, to attract and encourage empty nesters in rural area to participate in social activities and realize the happy aging. As a special group in society, empty nesters in rural area experience social reform and tough life, and each of them has their own advantages, specialty, interests and hobbies. The implementation of diversified fitness and cultural and artistic activities for the elderly, such as fitness competition, calligraphy and painting communication, and artistic performance, not only can create platforms for the elderly to strengthen communication and enhance emotion, also is helpful for them to realize their self-values and obtain sense of identity and happiness from social activities. Thirdly, to set up recruitment station for elderly volunteers, to recruit elderly volunteers who are enthusiastic about public welfare cause and have specialty, and to guide and encourage them to be participated in volunteer service activities and enrich their leisure life.

\subsection{From individuals: Empty nesters in rural area shall transform concept and strengthen their awareness and capacity of self-spiritual endowment.}

\subsubsection{To foster the awareness of self-spiritual endowment.}

In the developing times and progressing society, empty nesters in rural area shall transform their traditional idea of 'bringing up sons to support parents in their old age". When children cannot accompany them, they should understand their children, shall not hold resentment towards children and give up on themselves, whereas, correctly deal with unpleasant matters in life, and actively adjust their mental attitudes in time. They shall foster strong awareness of self-support from the bottom of their heart and reduce the relying on children in mind. 


\subsubsection{To establish the concept of active aging and integrate into and adapt to the society in mind and action.}

One of important contents emphasized in active aging is that to guide those elderly people with social labor capacity to actively participate in social life, social construction and social development, so as to contribute to the society and fully realize their self-values according to their labor potential, work desire, life requirements and interests and hobbies. Empty nest elderly people in rural area can serve in rural community by virtue of their experience, wisdom and technique specialty accumulated in a long period of time. For instance, the elderly can give play to their advantages of experience to provide guidance in agricultural production. The elderly with artistic specialty can organize empty nesters in villages to be involved in activities such as sing and dancing, playing chess, story-telling, handicraft communication, etc. to realize the happy aging.

\subsubsection{To cultivate new interests and hobbies.}

Empty nester aged people have much lonely time, so the cultivation of new interests and hobbies can enrich their spiritual life and reduce the sense of loneliness, such as playing chess, dancing, gardening, paper-cutting and so on. At the same time, they can find partners with same interests and hobbies, make new friends, expand social circle and enhance participation in social activities.

\section{Acknowledgements}

This work is the phased result of scientific research project of Xi'an Peihua University, "Research on Problems in Spiritual Endowment for Empty Nesters in Rural Area under the Background of Aging Population” in 2017, Project No. PHKT17068.

\section{References}

[1] Zhao Sumei. Briefly on Positive Spirit Endowment of the Elderly [J]. Social Sciences Journal of Universities in Shanxi, 2014 (1).

[2] Song Quancheng, Cui Ruining. Theoretical Response to High-speed Aging Population- from Healthy Aging to Active Aging [J]. Shandong Social Sciences, 2013 (4).

[3] Wang Kun. Research on Re-employment of Younger Elderly People from Active Aging- Taking M District of Shenzhen as an Example [D], Shenzhen University, 2017, 5.

[4] Xing Bo. Research on Spiritual Consolation for Empty Nesters in Rural Area and Its Implementation Path [J]. Economic Research Guide, 2017 (12).

[5] Zhou Xianglian, Zhou Yong. On Spiritual Endowments for the Empty Nesters in Rural Areas [J]. Journal of Hunan University of Science \& Technology (Social Science Edition), 2014 (7).

[6] Liu Yufeng. Focus on Spiritual Life of the Elderly [N]. Qingdao Daily, November 21, 2009, (006). 